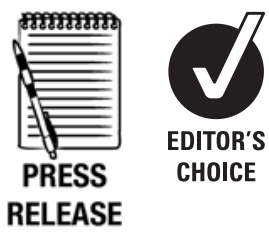

\title{
Neurobehavioral effects of long-term exposure to pesticides: results from the 4-year follow-up of the PHYTONER Study
}

\author{
Isabelle Baldi, ${ }^{1,2}$ Anne Gruber, ${ }^{1}$ Virginie Rondeau, ${ }^{2}$ Pierre Lebailly, ${ }^{3}$ Patrick Brochard, ${ }^{1}$ \\ Colette Fabrigoule ${ }^{4}$
}

- Additional tables are published online only. To view these files please visit the journal online (http://oem.bmj. com).

'Laboratoire Santé Travail Environnement, EA 3672. Institut de Santé Publique d'Epidémiologie et de Développement, IFR 99, Université Victor Segalen Bordeaux 2, Bordeaux, France ${ }^{2}$ Centre INSERM U897, Université Victor Segalen Bordeaux 2, Bordeaux, France ${ }^{3}$ Groupe Régional d'Etudes sur le Cancer, EA 1772, Centre François Baclesse, Université de Caen, Caen, France ${ }^{4}$ CNRS, UMR 5231, Université Victor Segalen Bordeaux 2, Bordeaux, France

\section{Correspondence to}

Isabelle Baldi, Laboratoire Santé Travail Environnement, EA 3672, Institut de Santé Publique d'Epidémiologie et de Développement, 146 rue Léo Saignat, 33076 Bordeaux cedex, France; isabelle.baldi@isped. u-bordeaux2.fr

Accepted 17 January 2010 Published Online First 22 November 2010

\begin{abstract}
Objective The aim of the PHYTONER study is to investigate the role of pesticides on neurobehavioral performances in French vineyard workers.
\end{abstract}

Methods 929 workers affiliated to the health insurance system for farmers in the Bordeaux area of south-western France were enrolled in the study in 1997-1998. They were contacted for a first follow-up in 2001-2003. Participants completed a questionnaire and nine neurobehavioral tests. They were classified according to their life-long pesticide exposure, as directly exposed, indirectly exposed or non-exposed. Educational level, age, sex, alcohol consumption, smoking, psychotropic drug use and depressive symptoms were taken into account in the analysis.

Results 614 subjects were available for investigation at follow-up. Follow-up analysis confirmed that the risk of obtaining a low performance on the tests was higher in exposed subjects, with ORs ranging from 1.35 to 5.60 . Evolution of performances over the follow-up period demonstrated that exposed subjects had the worst decreases in performance. The risk of having a two-point lower score on the Mini-Mental State Examination was 2.15 (95\% Cl 1.18 to 3.94$)$ in exposed subjects.

Conclusion These results suggest long-term cognitive effects of chronic exposure to pesticides and raise the issue of the risk of evolution towards dementia. The PHYTONER study is the first to provide prospective data on the natural history of neurological disorders associated with pesticide exposure.

There is growing evidence that pesticides may harm humans and cause cancers ${ }^{1}$ and neurological diseases $^{2}$ and have reproductive effects. ${ }^{3}$ In addition to non-specific neurological symptoms, exposure to pesticides might also be associated with psychiatric disorders such as anxiety or depression, ${ }^{4}$ neurobehavioral impairment ${ }^{5}$ and neurodegenerative diseases like Parkinson's disease ${ }^{67}$ or Alzheimer's disease. ${ }^{8}$ It is well known that acute exposure to some insecticides (organophosphates, carbamates) can produce short-term effects through cholinesterase inhibition. It is also known that other insecticides (such as organochlorines or pyrethroids) are responsible for acute neurotoxic effects through alteration of the function of the ion channel (increasing sodium influx or decreasing chloride efflux). ${ }^{9}$ Other mechanisms have also been suggested, such as cytotoxicity due to free radical production (herbicides, eg, Paraquat), inhibition of mitochondrial functions (fungicides like maneb,

\section{What this paper adds}

- Despite growing evidence of adverse consequences, epidemiological data on neurobehavioral effects resulting from chronic exposure to pesticides are limited.

- Follow-up of a cohort of vineyard workers in south-western France showed that poor performances observed at baseline in subjects exposed to pesticides were sustained.

- Moreover, evolution over 4-5 years demonstrated that exposed subjects had the greatest decrease in performances with time.

- These results suggest possible evolution towards Alzheimer's disease or other dementias in subjects chronically exposed to pesticides.

and insecticides like rotenone) and activation or blocking of receptors (insecticides like nicotine, and neonicotinoids like imidacloprid). ${ }^{10}$ However, it is still controversial whether long-term neuropsychological sequelae occur and if permanent abnormalities follow acute toxic episodes. Epidemiological data are also very limited on the longterm effects of chronic exposure without acute symptoms, although some studies have demonstrated lower cognitive performances in subjects chronically exposed to pesticides. ${ }^{2}$ Regarding acute effects, most studies have focused on cholinesterase inhibitors. The question of long-term disturbances such as neurodegenerative diseases can only be answered by follow-up studies of exposed populations. In 1997, a cohort was recruited from among French vineyard workers for a study of the link between long-term pesticide exposure and neurobehavioral impairment. The first phase of this study demonstrated lower neuropsychological performances in people directly or indirectly exposed to pesticides. ${ }^{11}$

The aim of the present work was to examine the neurobehavioral performance of participants 4-5 years after enrolment and to compare performance evolution according to occupational exposure to pesticides.

\section{MATERIALS AND METHODS \\ Population}

The method used in the PHYTONER study has been described in detail elsewhere. ${ }^{11}$ In brief, 929 subjects were recruited from February 1997 to 
December 1998 in south-western France from a health insurance system for people involved in agriculture (MSA). Subjects had to have been 40-55 years old in 1995, to have been employed for $1000 \mathrm{~h}$ or more in the year 1995 and to have been affiliated to MSA from 1975 to 1995 (so that they had a minimum of 20 years of work in agriculture at enrolment). They were initially categorised into three groups (no pesticide exposure, direct exposure and indirect exposure) following examination of detailed job calendars. All participants were interviewed and completed a battery of nine neurobehavioral tests at baseline. Subjects were informed of the 4-year follow-up by their occupational physicians and were phoned to arrange interviews at home with a psychologist from May 2001 to December 2003. Subjects who could not be contacted were sought at length using phone data bases and by questioning their neighbours at their enrolment address.

Enrolment and follow-up questionnaires included detailed information on individual characteristics (age, sex, educational level), lifestyle (tobacco and alcohol consumption) and other factors likely to affect neurobehavioral status (depression, psychotropic drugs) or understanding of the test (nationality). ${ }^{11}$

\section{Exposure assessment}

Job calendars collected at enrolment included the dates of the start and end of each job, the exact title of the jobs and tasks performed (mixing or spraying of pesticides, cleaning of spraying equipment, or re-entry tasks). These data were entered for the period between enrolment and follow-up. After answers were reviewed, subjects were classified according to their entire life history as (i) 'directly exposed' if they had mixed or applied pesticides in vineyards, or cleaned or repaired spraying equipment in one or more job, (ii) 'certainly indirectly exposed' if they had never been directly exposed but had to perform tasks in contact with treated plants (re-entry tasks such as pruning or harvesting), (iii) 'possibly indirectly exposed' if they had worked in a vineyard (in offices, buildings, cellars, etc) but reported no contact with treated plants, or (iv) 'non-exposed' if not classified in one of the above categories. We took into consideration the season of the interview (during or outside the main treatment period in vineyards, that is, May to August), to take account of the effect of any recent exposure. We also noted any history of acute poisoning with pesticides.

\section{Neurobehavioral tests}

The neuropsychological battery of tests administered at followup by a trained psychologist with standardised material comprised nine tests (a detailed description of these tests is given in online supplementary table 1):

i. The Mini-Mental State Examination (MMSE) ${ }^{12}$

ii. The Wechsler Paired-Associates Test (WPAT) ${ }^{13} 14$

iii. The multiple choice (form F) of the Benton Visual Retention Test (BVRT) ${ }^{15}$

iv. The Five Words Test (FWT) ${ }^{16}$

v. Part A of the Trail Making Test $(\mathrm{TMT})^{17}$

vi. The Isaacs Set Test (IST) ${ }^{18}$

vii. The Finger Tapping Test (FTT) ${ }^{19}$

viii. A modified version of the Stroop Test (ST) 2021

ix. The Wechsler Similarities Test (WST). ${ }^{13}$

\section{Analysis}

Analysis was performed with SAS 8.2. Characteristics of subjects, exposure conditions and neurobehavioral performances were described and compared with usual tests ( $\chi^{2}$, ANOVA) with $\alpha=0.05$. The results of the tests did not follow a normal distribution and were considered as dichotomous variables. The threshold was determined from the distribution of the performances at enrolment for the whole population. For all tests, we compared the $25 \%$ of subjects with the lowest performances with the rest. This corresponded to the 25th percentile of the distribution when an elevated value corresponded with a good performance (eg, number of good answers) and the 75th percentile when it did not (eg, time to achieve a performance). As the FWT was introduced at follow-up, the threshold was determined from the distribution at that time. To assess the stability of our results, we also used the 10th and 90th percentiles when numbers were large enough to allow running of multivariate models. In the main analyses, exposure was considered in three classes (no exposure, direct exposure and indirect exposure). We also performed some analyses separating those certainly indirectly exposed and those possibly indirectly exposed. We studied the association between reports of acute poisoning with pesticides and the results of the tests.

Multivariate logistic regression was used to analyse the association between performances at follow-up and pesticide exposure. Potential confounders were sex, age, educational level, nationality, alcohol consumption, tobacco smoking, depression, and psychotropic drug consumption for therapeutic use. Age sex, education and variables associated with neurobehavioral performances and exposure in univariate analysis with $p<0.25$ were retained in multivariate models. To take account of potential residual confounding, stratifications on sex, educational level and alcohol consumption were performed. We also separately analysed subjects interviewed during or outside the treatment season to control for a short-term effect of pesticide exposure.

For the 614 subjects interviewed at follow-up, evolution of performances between enrolment and follow-up was compared according to workers' pesticide exposure. Differences between scores at follow-up and enrolment allowed us to generate a dichotomous variable that differentiated subjects with the largest decreases in performance (threshold: 25 th percentile of the distribution of the differences in scores) from the rest. Afterwards the global strategy of analysis was the same as described above for the cross-sectional analysis, except that delay between enrolment and follow-up was added into the models. We also constructed models excluding subjects with a report of acute pesticide poisoning. Finally, analyses were conducted with subjects who refused tests at follow-up classified with subjects with the most evolution.

\section{RESULTS}

\section{Study population}

A total of 625 (67.3\%) of the 929 subjects enrolled in the cohort were interviewed. The time from baseline to follow-up averaged 4.7 years. Characteristics of subjects according to their participation status are presented in table 1. Among the 304 nonresponders, $57.6 \%$ declined the follow-up, $24.0 \%$ could not be contacted, $8.9 \%$ consented first but refused later on, $7.6 \%$ were deceased and $1.6 \%$ had moved away from the area. Eleven subjects had direct exposure to crops other than vines and were excluded from the analysis to maintain homogeneity in exposure conditions. Non-participants were comparable to participants on most characteristics but were slightly older, less educated, and had higher alcohol consumption. Results on most of the tests at baseline were significantly lower in non-participants (results not shown). The mean age of the cohort was approximately 55 years (table 2) and did not differ according to pesticide exposure. About $80 \%$ of the subjects were men but this 
Table 1 Characteristics of subjects at baseline according to their participation at follow-up

\begin{tabular}{|c|c|c|c|c|c|c|c|}
\hline \multirow[b]{2}{*}{ Characteristics } & \multicolumn{2}{|c|}{$\begin{array}{l}\text { No } \\
(n=304)\end{array}$} & \multicolumn{2}{|c|}{$\begin{array}{l}\text { Yes } \\
(n=614)\end{array}$} & \multirow[b]{2}{*}{ p Value } & \multicolumn{2}{|c|}{$\begin{array}{l}\text { Total } \\
(n=918)\end{array}$} \\
\hline & $\mathbf{n}$ & $\%$ & $\mathbf{n}$ & $\%$ & & $\mathbf{n}$ & $\%$ \\
\hline Age, mean (years) & \multicolumn{2}{|c|}{51.5} & \multicolumn{2}{|c|}{50.1} & $<10^{-3}$ & \multicolumn{2}{|c|}{50.5} \\
\hline \multicolumn{8}{|l|}{ Sex } \\
\hline Male & 253 & 83.2 & 486 & 79.2 & 0.14 & 739 & 80.5 \\
\hline Female & 51 & 16.8 & 128 & 20.8 & & 179 & 19.5 \\
\hline \multicolumn{8}{|l|}{ Educational level } \\
\hline Lower & 173 & 56.9 & 283 & 46.1 & 0.002 & 456 & 49.7 \\
\hline Certificat d'études* & 131 & 43.1 & 331 & 53.9 & & 462 & 50.3 \\
\hline \multicolumn{8}{|l|}{ Nationality } \\
\hline French & 261 & 85.9 & 534 & 87.0 & 0.64 & 795 & 86.6 \\
\hline Other & 43 & 14.1 & 80 & 13.0 & & 123 & 13.4 \\
\hline \multicolumn{8}{|l|}{ Smoking } \\
\hline Non-smokers & 121 & 40.1 & 256 & 41.9 & 0.60 & 377 & 41.3 \\
\hline Former or current smokers & 181 & 59.9 & 355 & 58.1 & & 536 & 58.7 \\
\hline \multicolumn{8}{|l|}{ Alcohol } \\
\hline No or moderate consumption & 177 & 61.0 & 398 & 68.7 & 0.02 & 575 & 66.2 \\
\hline Excessive consumption & 113 & 39.0 & 181 & 31.3 & & 294 & 33.8 \\
\hline \multicolumn{8}{|l|}{ Psychotropic drugs } \\
\hline Yes & 26 & 8.6 & 48 & 7.8 & 0.70 & 74 & 8.1 \\
\hline No & 278 & 91.4 & 566 & 92.2 & & 844 & 91.9 \\
\hline \multicolumn{8}{|l|}{ Depressive symptoms } \\
\hline Yes & 15 & 5.5 & 34 & 5.7 & 0.92 & 49 & 5.6 \\
\hline No & 257 & 94.5 & 565 & 94.3 & & 822 & 94.4 \\
\hline \multicolumn{8}{|l|}{ Pesticide exposure } \\
\hline No & 43 & 14.4 & 121 & 19.7 & 0.12 & 164 & 18.0 \\
\hline Direct exposure & 176 & 59.1 & 329 & 53.6 & & 505 & 55.4 \\
\hline Indirect exposure & 79 & 26.5 & 164 & 26.7 & & 243 & 26.6 \\
\hline
\end{tabular}

${ }^{*}$ Certificate formerly obtained at the end of primary school education.

proportion ranged from $40 \%$ in certainly indirectly exposed subjects to $99 \%$ in directly exposed.

The level of education was lower in exposed subjects, except in subjects possibly indirectly exposed, a category including clerical workers in vineyards. Foreigners were mainly Portuguese (6.7\%), Moroccans (4.6\%) and Spanish (1.6\%). About 21\% of the subjects were classified as heavy drinkers, a proportion similar in the exposed and non-exposed categories, and higher in men $(23.3 \%)$ than in women (11.8\%). Among these, $75.8 \%$ had already been classified as heavy drinkers at baseline, while $19.0 \%$ of subjects with a non-excessive consumption at follow-up were former heavy drinkers. About $10 \%$ of subjects were taking psychotropic drugs at follow-up; $47.5 \%$ of them had already been psychotropic drug consumers at baseline, while $3.4 \%$ of non-medicated subjects at follow-up had formerly taken psychotropic drugs.

\section{Exposure characteristics}

Among the 614 subjects, $19.4 \%$ had never been occupationally exposed to pesticides, $8.5 \%$ were possibly indirectly exposed, $17.4 \%$ had been certainly indirectly exposed and $54.7 \%$ had been directly exposed.

Subjects with certain indirect exposure had performed tasks involving contact with vines for an average of 24 years (SD 10.5 years; range $1-44$ years). Thirty-five (32.7\%) were still involved in tasks involving contact with vines when interviewed, while the others had not been exposed for an average of 10 years (SD 12.4 years).

Most of the directly exposed subjects had sprayed pesticides (97\%), 83\% had also mixed pesticides and $80 \%$ had also cleaned their spraying equipment. Duration of direct exposure was
24 years on average. Most of the directly exposed subjects (96.7\%) had also been indirectly exposed. Overall, 219 (65.2\%) were still directly exposed when interviewed, and 117 (34.8\%) had not been directly exposed for 17 years on average.

For 227 subjects $(37.0 \%)$, the interview took place during the season of pesticide use.

Eighty-seven subjects (14.2\%) reported a history of acute pesticide poisoning at a mean of 13.4 years $(0-38$ years) before the interview (the time interval was known for $65.5 \%$ of these subjects)

\section{Results of neurobehavioral tests}

Participation rate for the tests ranged from $89.7 \%$ (ST) to $99.8 \%$ (MMSE). The entire battery of tests was completed by $85.8 \%$ of subjects and $97.9 \%$ took six tests or more. Table 3 presents the 25 th and 10 th percentiles of the distributions of the performances at follow-up, and of the differences in the scores between baseline and follow-up. An increase in 1 year in age was associated with a $5-16 \%$ increase in risk of performing poorly (table 4). Men had a higher risk of poor performances on all the tests except the FTT and the ST. A low level of education was also associated with a risk of low performance on all tests. Excessive alcohol intake, depressive symptoms and psychotropic drug intake tended to increase the risk of low performance on most of the tests, but this was significant only for the MMSE and IST for alcohol and for the WPAT for psychotropic drug use (see supplementary online table 2 for detailed results).

\section{Neurobehavioral performances and pesticide exposure at follow-up}

In univariate analysis comparing exposed with non-exposed subjects, the strength of the crude association ranged from 1.77 for the FWT to 12.05 for the BVRT and was statistically significant for all tests except the WST $(p=0.10)$. The increase in risk was seen in both directly and indirectly exposed subjects and the strength of the association was slightly lower in the indirectly exposed (from 1.16 for the FWT to 10.69 for the BVRT) compared to the directly exposed (from 2.18 for the FWT to 12.73 for the BVRT) for all tests except the FTT. When adjusting on confounders, exposed subjects remained at higher risk of performing poorly on every test apart from the WST (figure 1). Three tests were associated with the two types of exposure and also presented the highest risks (BVRT, OR 5.84 in directly and 5.36 in indirectly exposed subjects; TMT, OR 3.47 in directly and 5.3 in indirectly exposed subjects; and STg (Stroop good answers), OR 2.82 in directly and 2.60 in indirectly exposed subjects). Five tests were influenced by only one type of exposure. Risks were sometimes higher in directly exposed (MMSE, WPTd (Wechsler Paired Test difficult items), BVRT, WST, FWT) and sometimes higher in indirectly exposed (TMT, IST, FTTnp (Finger Tapping Test non-preferred hand)) subjects. When subjects possibly indirectly exposed were considered separately, their risk of poor performance was lower than in those certainly indirectly exposed, ranging from 0.48 for the MMSE to 2.85 for the TMT compared to the non-exposed subjects. Separating indirect exposure into possible and certain changed the ranking between categories: the certainly indirectly exposed showed higher risks than the directly exposed on all the tests except the MMSE, WPTe (Wechsler Paired Test easy items) and FWT.

When multivariate analysis were performed with the 10th-90th percentiles, some associations with exposure were stronger and more statistically significant: in the directly exposed, ORs were 8.96 (95\% CI 1.18 to 68.10) for the BVRT, 
Table 2 Characteristics of subjects at follow-up according to pesticide exposure

\begin{tabular}{|c|c|c|c|c|c|c|c|c|c|c|c|c|}
\hline \multirow{3}{*}{ Characteristics } & \multicolumn{10}{|c|}{ Pesticide exposure } & & \\
\hline & \multirow{2}{*}{\multicolumn{2}{|c|}{ No $(n=119)$}} & \multirow{2}{*}{\multicolumn{2}{|c|}{$\begin{array}{l}\text { Direct } \\
(n=336)\end{array}$}} & \multicolumn{4}{|c|}{ Indirect exposure } & & & \multirow{2}{*}{\multicolumn{2}{|c|}{ Total $(n=614)$}} \\
\hline & & & & & \multicolumn{2}{|c|}{$\begin{array}{l}\text { Certain } \\
(n=107)\end{array}$} & \multicolumn{2}{|c|}{$\begin{array}{l}\text { Possible } \\
(n=52)\end{array}$} & \multicolumn{2}{|c|}{$\begin{array}{l}\text { All exposed } \\
(\mathrm{n}=495)\end{array}$} & & \\
\hline Age, means (years) & \multicolumn{2}{|l|}{54.3} & \multicolumn{2}{|l|}{55.1} & \multicolumn{2}{|l|}{54.9} & \multicolumn{2}{|l|}{53.8} & \multicolumn{2}{|l|}{54.9} & \multicolumn{2}{|c|}{54.8} \\
\hline \multicolumn{13}{|l|}{ Sex } \\
\hline \multicolumn{13}{|l|}{ Educational level } \\
\hline Lower & 13 & 10.9 & 198 & 58.9 & 67 & 62.6 & 5 & 9.6 & 270 & 54.5 & 283 & 46.1 \\
\hline Certificat d'études* and higher & 106 & 89.1 & 138 & 41.1 & 40 & 37.4 & 47 & 90.4 & 225 & 45.5 & 331 & 53.9 \\
\hline \multicolumn{13}{|l|}{ Nationality } \\
\hline French & 113 & 95.0 & 282 & 83.9 & 87 & 81.3 & 52 & 100.0 & 421 & 85.1 & 534 & 87.0 \\
\hline Other & 6 & 5.0 & 54 & 16.1 & 20 & 18.7 & 0 & 0.0 & 74 & 14.9 & 80 & 13.0 \\
\hline No or moderate consumption & 92 & 78.6 & 263 & 78.3 & 85 & 79.4 & 44 & 84.6 & 392 & 79.2 & 484 & 79.1 \\
\hline Excessive consumption & 25 & 21.4 & 73 & 21.7 & 22 & 20.6 & 8 & 15.4 & 103 & 20.8 & 128 & 20.9 \\
\hline \multicolumn{13}{|l|}{ Psychotropic drugs } \\
\hline Yes & 10 & 8.4 & 38 & 11.3 & 10 & 9.3 & 3 & 5.8 & 51 & 10.3 & 61 & 9.9 \\
\hline No & 109 & 91.6 & 298 & 88.7 & 97 & 90.7 & 49 & 94.2 & 444 & 89.7 & 553 & 90.1 \\
\hline \multicolumn{13}{|l|}{ Depressive symptoms } \\
\hline Yes & 4 & 3.4 & 23 & 6.9 & 5 & 4.8 & 2 & 3.9 & 30 & 6.1 & 34 & 5.6 \\
\hline No & 115 & 96.6 & 312 & 93.1 & 100 & 95.2 & 49 & 96.1 & 461 & 93.9 & 576 & 94.4 \\
\hline Duration of follow-up, mean (months) & 53.8 & & 57.1 & & 57.9 & & 55.1 & & 57.1 & & 56.4 & \\
\hline \multicolumn{13}{|c|}{ Interview during treatment period (May-August) } \\
\hline Yes & 34 & 28.6 & 129 & 38.4 & 44 & 41.1 & 20 & 38.5 & 193 & 39.0 & 227 & 37.0 \\
\hline No & 85 & 71.4 & 207 & 61.6 & 63 & 58.9 & 32 & 61.5 & 302 & 61.0 & 387 & 63.0 \\
\hline
\end{tabular}

${ }^{*}$ Certificate formerly obtained at the end of primary school education.

10.30 (95\% CI 1.35 to 78.57$)$ for the STg and 5.96 (95\% CI 1.37 to 25.98 ) for the STb (Stroop bad answers).

\section{Changes in neurobehavioral performances (between baseline and follow-up) and pesticide exposure}

Globally, the proportion of subjects who improved their performances at follow-up varied from $21.2 \%$ (the STb) to $48.7 \%$ (the TMT) and the proportion of subjects who had worse scores ranged from $15.4 \%$ (the WST) to $51.5 \%$ (MMSE). Except for the WPT and WST, participants whose scores worsened the most (being in the $25 \mathrm{th}-75 \mathrm{th}$ percentile of the distribution of the differences of scores) were more frequently exposed subjects, especially for the MMSE ( $p=0.001)$ and the STb $(p=0.01)$.

In multivariate analysis taking into account the type of exposure, the association between pesticide exposure and severe worsening appeared significant on the MMSE (OR 1.97, 95\% CI 1.09 to 3.59 ) in the directly exposed and on the STb (OR 2.08, $95 \%$ CI 1.09 to 3.96 ) in the indirectly exposed.

When considering direct and indirect exposure separately, the association appeared significant in the directly exposed for the MMSE and in the indirectly exposed for the STb (OR 2.08).

The association between exposure and results on the tests was stronger in women and in better educated subjects for the MMSE and the ST and also stronger in no or low alcohol consumers for the MMSE (figure 2).

When missing data on the tests were classified as poor performances, there was little change, except for the STg, where a significant result was observed for indirectly exposed subjects (OR $1.79,95 \%$ CI 1.02 to 3.16 ).

Excluding subjects reporting acute poisoning slightly changed the strength of the associations (data not shown). However, in directly exposed subjects, two non-significant results became significant (the TMT and FTTp (Finger Tapping Test preferred hand)). The risk of a large decrease in performances on the MMSE changed from 1.95 (95\% CI 1.09 to 3.96$)$ to 1.89 (95\% CI 1.02 to 3.50$)$.

\section{DISCUSSION}

Follow-up of the PHYTONER cohort showed lower cognitive performances in pesticide-exposed subjects. Among the seven cognitive tests significantly associated with pesticide exposure, three have a cognitive speed component: (i) the TMT, also implying a selective attention component, (ii) the FTT, a very simple motor speed test with a strategic component and (iii) the IST, a semantic verbal fluency test which implies integrity of semantic memory, as well as strategic search, working memory and a speed component. Performance on two of these tests with a speed component have already been found to be associated with chronic pesticide exposure (the $\mathrm{TMT}^{22-24}$ ) as has often been found with other cognitive speed tests, such as the TMT part B 222526 and the Digit Symbol Substitution Test. 2224252728 The most strongly associated test, the BVRT, is a visual working memory test, which also implies selective attention and inhibition, and this test and other quite similar ones have already been 
Table 3 Description of the tests and definition of parameters used in the analysis and thresholds (percentiles) for test performances

\begin{tabular}{|c|c|c|c|c|c|c|c|}
\hline Tests & Description of the tests & $\begin{array}{l}\text { Parameters used } \\
\text { in the analysis }\end{array}$ & $\begin{array}{l}\text { Theoretical } \\
\text { performances }\end{array}$ & $\begin{array}{l}\text { 25th/75th } \\
\text { percentile }\end{array}$ & $\begin{array}{l}\text { 10th/90th } \\
\text { percentile }\end{array}$ & $\begin{array}{l}\text { 25th/75th } \\
\text { percentile }\end{array}$ & $\begin{array}{l}\text { 10th/90th } \\
\text { percentile }\end{array}$ \\
\hline MMSE & $\begin{array}{l}\text { Global scale measuring different cognitive } \\
\text { components: orientation to time and } \\
\text { place, registration of three words, } \\
\text { attention and calculation, recall of three } \\
\text { words, language, and visual construction. }\end{array}$ & Total score & 0 to 30 & 24 & 22 & -2 & -3 \\
\hline WPTe & \multirow[b]{2}{*}{$\begin{array}{l}\text { Verbal associative memory test, involving } \\
\text { the reading of } 10 \text { word pairs. After } \\
\text { reading the list, the examiner gives the } \\
\text { first word of each pair and the subject is } \\
\text { asked to provide the second word. Only } \\
\text { one learning trial and a delayed recall are } \\
\text { performed. Six of the word pairs are easy } \\
\text { associations (eg, baby-cries) and four } \\
\text { are difficult (eg, cabbage-pen). The easy } \\
\text { pairs are given a score of } 5 \text { and the } \\
\text { difficult ones a score of } 10 \text {. }\end{array}$} & \multirow{2}{*}{$\begin{array}{l}\text { Scores to first recall } \\
\text { of difficult (WPTd) } \\
\text { and easy (WPTe) } \\
\text { word pairs separately }\end{array}$} & 0 to 40 & 0 & 0 & -10 & -10 \\
\hline WPTd & & & 0 to 30 & 15 & 10 & -5 & -10 \\
\hline BVRT & $\begin{array}{l}\text { Visual test consisting of } 15 \text { stimulus cards } \\
\text { and } 15 \text { multiple choice cards. After } \\
\text { presentation of a stimulus card for } 10 \mathrm{~s} \text {, } \\
\text { the subjects were asked to choose the } \\
\text { initial figure among four options. }\end{array}$ & Total score & 0 to 15 & 9 & 8 & -1 & -2 \\
\hline FWT & $\begin{array}{l}\text { A verbal episodic memory test based on } \\
\text { five words. After semantic encoding, an } \\
\text { immediate free recall is performed, } \\
\text { followed by a semantic cued recall for } \\
\text { forgotten words (eg: when 'truck' is } \\
\text { forgotten, the semantic cue was 'what } \\
\text { was the name of the vehicle?'). After } \\
\text { a non-verbal interference test (TMT A and } \\
\text { B), a delayed recall is performed, } \\
\text { including free and cued recalls. }\end{array}$ & $\begin{array}{l}\text { Sum of the immediate } \\
\text { and delayed free recalls }\end{array}$ & 0 to 10 & 8 & 7 & NA & NA \\
\hline TMT A & $\begin{array}{l}\text { Test measuring processing speed. } \\
\text { Consists of connecting as fast as possible } \\
\text { and in numerical order numbers (from } 1 \text { to } \\
\text { 25) randomly located on a card. Before } \\
\text { the test, a pre-test was given to ensure } \\
\text { instructions had been understood. } \\
\text { Contrary to the usual procedure, the } \\
\text { psychologist allowed subjects to continue } \\
\text { the task without any further help or } \\
\text { rectification. Time was recorded } \\
\text { independently of correct connections and } \\
\text { errors. }\end{array}$ & $\begin{array}{l}\text { Ratio of correct } \\
\text { connections to the } \\
\text { time of the TMT A }\end{array}$ & 0 to $\infty$ & 2.92 & 3.67 & +0.29 & +0.71 \\
\hline IST & $\begin{array}{l}\text { Test measuring the ability to generate } \\
\text { words in four specific semantic categories } \\
\text { (colours, animals, fruits, cities) in a limited } \\
\text { time. }\end{array}$ & $\begin{array}{l}\text { Number of words } \\
\text { generated in each } \\
\text { category in } 60 \mathrm{~s}\end{array}$ & 0 to $\infty$ & 46 & 40 & -6 & -12 \\
\hline FTTp & \multirow[b]{2}{*}{$\begin{array}{l}\text { Test measuring motor speed. The subject } \\
\text { had to press a tapping key as many times } \\
\text { as possible in } 15 \mathrm{~s} \text {. Two trials were } \\
\text { performed: one with the preferred hand } \\
\text { (FTTp) and one with the non-preferred } \\
\text { hand (FTTnp). }\end{array}$} & \multirow{2}{*}{$\begin{array}{l}\text { Scores at the } \\
\text { second trial for } \\
\text { each hand }\end{array}$} & 0 to $\infty$ & 60 & 51 & -5 & -9 \\
\hline FTTnp & & & 0 to $\infty$ & 53 & 47 & -4 & -7 \\
\hline STg & \multirow[b]{2}{*}{$\begin{array}{l}\text { A card containing five columns of } 10 \text { sets } \\
\text { of symbols (colour names: blue, red, } \\
\text { yellow, green, printed in contrasting ink) } \\
\text { was presented to the subject. He had to } \\
\text { name the ink colour while ignoring the } \\
\text { meaning of the word. }\end{array}$} & \multirow{3}{*}{$\begin{array}{l}\text { Numbers of good } \\
\text { (STg) and bad answers } \\
\text { (excluding corrected } \\
\text { errors) (STb) }\end{array}$} & 0 to 50 & 47 & 44 & -1 & -2 \\
\hline STb & & & 0 to 50 & 1 & 3 & 0 & +2 \\
\hline WST & $\begin{array}{l}\text { The subject had to explain in what way } \\
\text { two things were alike (eg } \\
\text { 'orange-banana'). Only the first five pairs } \\
\text { of the WST were considered. Two points } \\
\text { were given for an abstract generalisation } \\
\text { and one point if a response was a specific } \\
\text { concrete likeness. }\end{array}$ & & 1 to 10 & 5 & 3 & 0 & -1 \\
\hline
\end{tabular}

BVRT, Benton Visual Retention Test; FTTnp, Finger Tapping Test non-preferred hand; FTTp, Finger Tapping Test preferred hand; IST, Isaacs Set Test; MMSE, Mini-Mental State Examination STb, Stroop bad answers; STg, Stroop good answers; TMT, Trail Making Test; WPTd, Wechsler Paired Test difficult items; WPTe, Wechsler Paired Test easy items; WST, Wechsler Similarities Test. For the TMT and STb, thresholds correspond to the 25th or 10th percentiles of the distribution as an increase in the value corresponds to a lowering in performance.

shown to be associated with chronic pesticide exposure. ${ }^{22} 29-32$ The second most associated measure is the number of good answers on the Stroop interference test, implying selective attention and inhibition of an automatic response. Finally, performances on two episodic memory tests were also associated with pesticide exposure, as was the case with the Rey Auditory Verbal Learning Test in another study. ${ }^{32}$ Associations between pesticide exposure and test results were very strong with ORs for 
Table 4 Association between possible confounders and test results at 4-year follow-up

\begin{tabular}{|c|c|c|c|c|c|c|c|c|c|c|c|c|}
\hline & \multicolumn{2}{|l|}{ Age } & \multicolumn{2}{|c|}{ Sex (men vs women) } & \multicolumn{2}{|c|}{$\begin{array}{l}\text { Education (low level } \\
\text { vs high level) }\end{array}$} & \multicolumn{2}{|c|}{$\begin{array}{l}\text { Alcohol } \\
\text { (excessive vs no) }\end{array}$} & \multicolumn{2}{|c|}{$\begin{array}{l}\text { Depression } \\
\text { (yes vs no) }\end{array}$} & \multicolumn{2}{|c|}{$\begin{array}{l}\text { Psychotropic drugs } \\
\text { (yes vs no) }\end{array}$} \\
\hline MMSE & 1.05 & 1.01 to 1.09 & 1.92 & 1.20 to 3.08 & 8.62 & 5.71 to 12.99 & 1.55 & 1.03 to 2.33 & 1.27 & 0.61 to 2.62 & 1.43 & 0.83 to 2.48 \\
\hline WPTe & 1.08 & 1.04 to 1.13 & 2.06 & 1.28 to 3.29 & 3.52 & 2.44 to 5.05 & 0.99 & 0.64 to 1.51 & 0.68 & 0.30 to 1.54 & 1.88 & 1.09 to 3.26 \\
\hline BVRT & 1.09 & 1.04 to 1.14 & 1.49 & 0.87 to 2.55 & 7.52 & 4.57 to 12.35 & 1.48 & 0.92 to 2.35 & 1.42 & 0.62 to 3.24 & 1.73 & 0.95 to 3.16 \\
\hline FWT & 1.05 & 1.01 to 1.09 & 1.69 & 1.13 to 2.53 & 1.27 & 0.91 to 1.78 & 0.83 & 0.55 to 1.25 & 1.00 & 0.47 to 2.13 & 1.28 & 0.73 to 2.24 \\
\hline FTTp & 1.08 & 1.04 to 1.13 & 0.49 & 0.32 to 0.74 & 2.67 & 1.85 to 3.86 & 1.46 & 0.96 to 2.24 & 1.52 & 0.70 to 3.29 & 1.68 & 0.95 to 2.98 \\
\hline FTTnp & 1.09 & 1.04 to 1.14 & 0.42 & 0.27 to 0.64 & 2.09 & 1.42 to 3.07 & 1.54 & 0.99 to 2.39 & 1.32 & 0.59 to 2.95 & 1.64 & 0.91 to 2.95 \\
\hline STg & 1.08 & 1.04 to 1.13 & 0.97 & 0.61 to 1.54 & 3.21 & 2.15 to 4.76 & 1.39 & 0.88 to 2.20 & 1.13 & 0.49 to 2.62 & 1.72 & 0.96 to 3.08 \\
\hline STb & 1.06 & 1.02 to 1.11 & 1.22 & 0.79 to 1.88 & 1.74 & 1.22 to 2.49 & 1.49 & 0.97 to 2.28 & 0.73 & 0.32 to 1.67 & 1.27 & 0.72 to 2.24 \\
\hline WST & 1.13 & 1.04 to 1.23 & 2.39 & 0.71 to 8.00 & 4.85 & 1.95 to 12.05 & 1.22 & 0.51 to 2.93 & 1.31 & 0.30 to 5.75 & 1.06 & 0.31 to 3.59 \\
\hline
\end{tabular}

ORs were calculated with univariate logistic regression analysis, with independent variables being performances on the tests, dichotomised according to the 25 th/75th percentile of their distribution (mentioned in table 3). Age was considered as a continuous variable.

BVRT, Benton Visual Retention Test; FTTnp, Finger Tapping Test non-preferred hand; FTTp, Finger Tapping Test preferred hand; IST, Isaacs Set Test; MMSE, Mini-Mental State Examination;

STb, Stroop bad answers; STg, Stroop good answers; TMT, Trail Making Test; WPTd, Wechsler Paired Test difficult items; WPTe, Wechsler Paired Test easy items; WST, Wechsler Similarities Test.

having a performance in the lower quarter of the distribution exceeding 5 for the visual working memory test (the BVRT) and 1 for the cognitive speed test (the TMT) and being even stronger for some cognitive measures if one considers the risk to be in the lower $10 \%$ of performances, with a risk multiplied by more than eight for the BVRT and more than 10 for the ST. No clear doseeffect relationship was observed between the directly and indirectly exposed. The evolution of performances over a 4-5-year period demonstrated that exposed subjects generally had the greatest decrease: on the MMSE they had a 1.97 risk of lowering their score by two points between baseline and follow-up compared to non-exposed subjects, and a 1.64 risk of lowering their score by three points. This result is particularly striking in view of the short duration of follow-up and the relatively young age of the participants.

A longitudinal study of performances in a French population aged 65 and over without dementia showed a slight decline over 5 years only in tests with a speed component, but not on the MMSE or the BVRT. ${ }^{33}$ The observed decline in pesticideexposed subjects on the MMSE, a composite measure reflecting global cognitive deterioration, cannot therefore be considered a sole effect of ageing, especially as the subjects were relatively young.

We also observed a stronger impact of pesticide exposure in groups who had protective characteristics at baseline with regard to cognitive performances (highly educated, no alcohol consumption, women) even if these groups had and continued to have a higher performance than others. Several studies have demonstrated that highly educated people have a lower risk of Alzheimer's disease and dementia, which is often explained by a hypothetic 'reserve capacity'. 3435 This 'reserve' might explain why their performances were better than those of the less educated subjects at baseline. They may initially resist pesticide exposure better, but their accelerated decline showed that prolonged exposure combined with ageing may considerably reduce their protective factors.

Our results were obtained on a sample unusually large for a study involving the administration of a battery of neurobehavioral tests. A review in 2004 by Kamel et al ${ }^{2}$ showed that more than half of 39 epidemiological studies on pesticide
Figure 1 Risks of performing poorly on a test at follow-up for the different tests according to pesticide exposure at 4-year follow-up. BVRT, Benton Visual Retention Test; FTTnp, Finger Tapping Test non-preferred hand; FTTp, Finger Tapping Test preferred hand; IST, Isaacs Set Test; MMSE, Mini-Mental State Examination; STb, Stroop bad answers; STg, Stroop good answers; TMT, Trail Making Test; WPTd, Wechsler Paired Test difficult items; WPTe, Wechsler Paired Test easy items; WST, Wechsler Similarities Test. ORs were calculated separately for directly and indirectly exposed subjects, with multivariate logistic regression analysis. Independent variables were performances on the tests, dichotomised according to the 25 th/75th percentile of their distribution (mentioned in table 3). All analysis were adjusted for age, sex and educational level, plus nationality for the BVRT,

TMT, FTTp, WST, plus smoking for the STb.

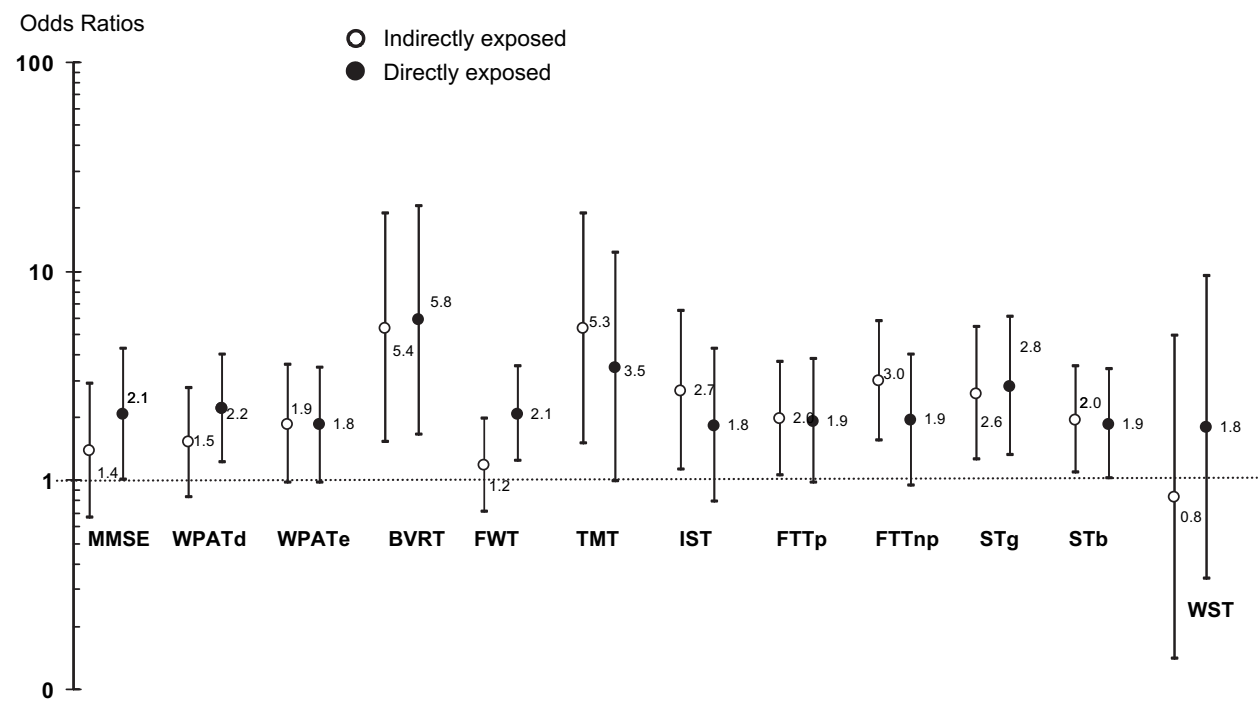


Figure 2 Risks of worsening scores on the MMSE and ST between enrolment and 4-year follow-up in exposed subjects according to individual characteristics. MMSE, MiniMental State Examination; STb, Stroop bad answers; STg, Stroop good answers. ORs for the MMSE, STg and STb were calculated in separate analyses for sex (adjusted for age, educational level and follow-up duration), educational level (adjusted for age, sex and follow-up duration) and alcohol consumption (adjusted for age, sex, educational level and follow-up duration). Independent variables were performances on the tests, dichotomised according to the 75th/25th percentile of their distribution (mentioned in table 3).

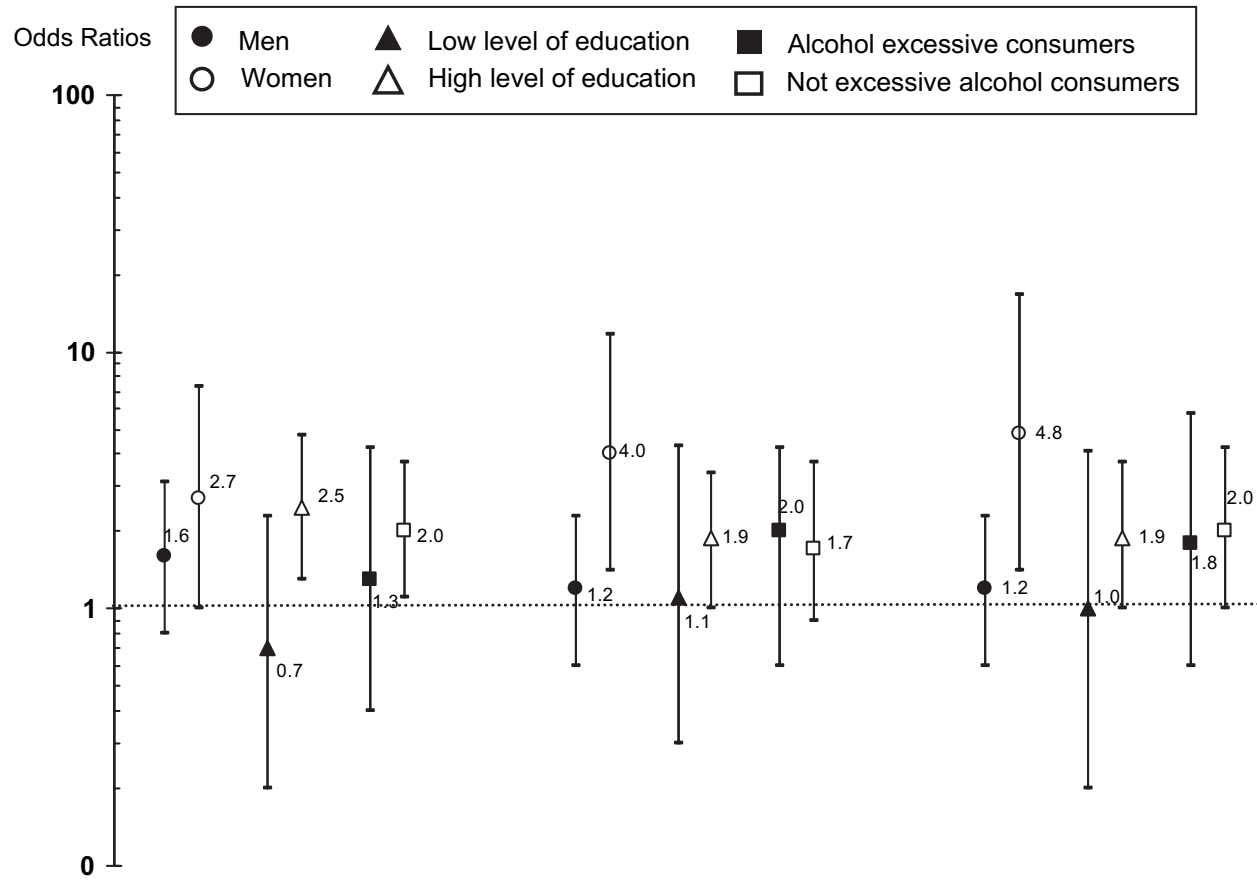

neurotoxicity included fewer than 100 exposed subjects and were not powerful enough to detect effects.

We also had the opportunity to reach farm workers, a population not often studied although occupationally vulnerable. ${ }^{36}$ About $70 \%$ of the baseline population was followed up and agreed to retesting. Non-participants had lower performances than participants at baseline so their non-participation could be related to difficulties they encountered in taking the tests. Some characteristics associated with lower performances (higher age and alcohol consumption, lower education level) were more frequent among non-participants which might have created a non-differential bias lowering the associations we found.

Our findings are consistent with previous results for farm workers who were found to be at higher risk of cognitive impairment, ${ }^{23} 3137-39$ although the agricultural settings varied between the studies and none were vineyards. The review by Kamel showed that among 21 studies on the cognitive effects of chronic pesticide exposure, $76 \%$ found positive associations with some tests and $82 \%$ found a relationship with psychomotor function. $^{2}$

In the present study we categorised subjects into groups of exposure from information provided in detailed job calendars including history of treatment tasks. It remains questionable whether indirectly exposed subjects in contact with treated plants really experienced lower cumulative levels than those directly exposed through treatment tasks, as re-entry tasks in vineyards are carried out on more days per year than treatment tasks, especially since the impact on cognitive effects did not differ much between these two categories of subjects.

The prospective design of this study demonstrated that the difference in performances between the exposed and non-exposed subjects was sustained. In some tests (the MMSE and ST), the decrease in performances appeared significantly worse in exposed workers, and was even worse if they had better performances at baseline. It should be underlined that some subjects, mostly those who were non-exposed, also had better results at follow-up than at baseline, which might be attributable to the well-known effect of practice when tests are repeated.

Our data suggest that the effects we observed cannot be fully explained by acute exposure. Indeed, low performances were not associated with the reporting of acute poisoning, taking the tests during the treatment season did not influence performances, and about half of the subjects were no longer exposed at the time of interview. Even taking major confounders into account, we cannot definitely rule out the possible role of suspected (solvents, metals, etc) or as yet unidentified risk factors in the neurobehavioral effects we observed.

Our analysis did not focus on specific pesticides. Indeed, a pilot stage revealed that workers did not know the names of the pesticides they were using, a situation partly explained by the fact that they were not in charge of purchasing them. Moreover, wine production requires many treatments, especially against various fungi. Considering that the oldest farmers started their occupational exposure in the 1970s and that latency is important, pesticides used in vineyards during the 1970 s and 1980s are of primary concern for the effects we observed. During that period, the most probable fungicides used were dithiocarbamates, phtalimides, dicarboximides, triazoles and inorganic substances (copper, sulphate, arsenic) with, to a lesser extent, insecticides (organophosphates, organochlorines and carbamates) and some herbicides (triazines or sulfamides). To date, most studies on the neurological impact of pesticides have examined organophosphates and carbamates, whose neurotoxicology has been largely elucidated. Moser recently underlined that cholinesterase inhibitors are not the only pesticides likely to produce long-term neurological effects in animals. ${ }^{40}$ Overall, 13 (81\%) of the 16 animal studies addressing cognitive impairment demonstrated a positive association with pesticide exposure.

The mild impairment we observed raises the question of the potentially higher risks of injury in this population and also of possible evolution towards neurodegenerative diseases such as Alzheimer's disease or other dementias. Numerous studies ${ }^{41-43}$ have shown that low cognitive performances are associated with risk of dementia. The recent review by Santibanez concluded there was a possible risk of Alzheimer's disease in relation to occupational exposure to pesticides, ${ }^{8}$ a finding particularly borne out by the data of Tyas et $a l^{44}$ and Baldi et $a l^{45}$ in their prospective studies. The 12th year of follow-up in our cohort should shed light on this important issue. 
Funding This study was funded by the Ministère de l'Environnement (Programme Santé Environnement), Agence Nationale pour I'Amélioration des Conditions de Travail, Conseil Régional d'Aquitaine, and Association Recherche et Partage.

Competing interests None.

Ethics approval This study was conducted with the approval of the ethics committee of Bordeaux Teaching Hospital.

Provenance and peer review Not commissioned; externally peer reviewed.

\section{REFERENCES}

1. Alavanja MC, Hoppin JA, Kamel F. Health effects of chronic pesticide exposure: cancer and neurotoxicity. Annu Rev Public Health 2004;25:155-97.

2. Kamel F, Hoppin JA. Association of pesticide exposure with neurologic dysfunction and disease. Environ Health Perspect 2004;112:950-8.

3. Weselak M, Arbuckle TE, Foster W. Pesticide exposures and developmental outcomes: the epidemiological evidence. J Toxicol Environ Health B Crit Rev 2007;10:41-80.

4. London L, Flisher AJ, Wesseling C, et al. Suicide and exposure to organophosphate insecticides: cause or effect? Am J Ind Med 2005:47:308-21.

5. Colosio C, Tiramani M, Maroni M. Neurobehavioral effects of pesticides: state of the art. Neurotoxicology 2003;24:577-91.

6. Priyadarshi A, Khuder SA, Schaub EA, et al. Environmental risk factors and Parkinson's disease: a metaanalysis. Environ Res 2001;86:122-7.

7. Brown TP, Rumsby PC, Capleton AC, et al. Pesticides and Parkinson's disease-is there a link? Environ Health Perspect 2006;114:156-64.

8. Santibanez M, Bolumar F, Garcia AM. Occupational risk factors in Alzheimer's disease: a review assessing the quality of published epidemiological studies. Occup Environ Med 2007;64:723-32.

9. Keifer MC, Firestone J. Neurotoxicity of pesticides. J Agromedicine 2007;12:17-25.

10. Costa LG, Giordano G, Guizzetti M, et al. Neurotoxicity of pesticides: a brief review. Front Biosci 2008;13:1240-9

11. Baldi I, Filleul L, Mohammed-Brahim B, et al. Neuropsychologic effects of long-term exposure to pesticides: results from the French Phytoner study. Environ Health Perspect 2001;109:839-44.

12. Folstein M, Folstein S, McHugh P. Mini-Mental State: A practical method for grading the cognitive state of patients for the clinician. J Psychiatr Res 1975;12:189-98.

13. Wechsler D. WAIS-R manuel. Cleveland: Psychological Corporation, 1981.

14. Amieva H, Rouch-Leroyer I, Fabrigoule $\mathrm{C}$, et al. Deterioration of controlled processes in the preclinical phase of dementia: a confirmatory analysis. Dement Geriatr Cogn Disord 2000;11:46-52.

15. Benton A. Manuel pour l'application du test de rétention visuelle. Applications cliniques et expérimentales. Paris: Centre de Psychologie Appliquée, 1965.

16. Dubois B, Touchon J, Portet F, et al. Les 5 mots: une épreuve simple et sensible pour le diagnostic de la maladie d'Alzheimer. Presse Med 2002;31:1696-9.

17. Reitan R. Validity of the Trail Making Test as an indicator of organic brain damage Percep Mot Skills 1965:8:271-6.

18. Isaacs B, Kennie A. The Set Test as an aid to the detection of dementia in old people. Br J Psychiatry 1973;45:957-62.

19. Halstead WC. Brain and intelligence. Chicago: University of Chicago Press, 1947.

20. Stroop JR. Studies of interference in serial verbal reactions. J Exp Psychol 1935: 18:643-62.

21. Amieva H, Lafont S, Rouch-Leroyer I, et al. Evidencing inhibitory deficits in Alzheimer's disease through interference effects and shifting disabilities on the Stroop test. Arch Clin Neuropsychol 2004;19:791-803.

22. Farahat TM, Abdelrasoul GM, Amr MM, et al. Neurobehavioural effects among workers occupationally exposed to organophosphorous pesticides. Occup Environ Med 2003:60:279-86.
23. Kamel F, Rowland AS, Park LP, et al. Neurobehavioral performance and work experience in Florida farmworkers. Environ Health Perspect 2003;111:1765-72.

24. Rothlein J, Rohlman D, Lasarev M, et al. Organophosphate pesticide exposure and neurobehavioral performance in agricultural and nonagricultural Hispanic workers. Environ Health Perspect 2006;114:691-6.

25. Daniell W, Barnhart S, Demers $P$, et al. Neuropsychological performance among agricultural pesticide applicators. Environ Res 1992;59:217-28.

26. Lizardi PS, O'Rourke MK, Morris RJ. The effects of organophosphate pesticide exposure on Hispanic childrens cognitive and behavioral functioning. J Pediatr Psychol 2008;33:91-101.

27. Stephens R, Spurgeon A, Calvert IA, et al. Neuropsychological effects of long-term exposure to organophosphates in sheep dip. Lancet 1995:345:1135-9.

28. Srivastava AK, Gupta BN, Bihari V, et al. Clinical, biochemical and neurobehavioura studies of workers engaged in the manufacture of quinalphos. Food Chem Toxicol 2000; 38:65-9.

29. Calvert GM, Mueller CA, Fajen JM, et al. Health effects associated with sulfuryl fluoride and methyl bromide exposure among structural fumigation workers. Am J Public Health 1998;88:1774-80.

30. Cole DC, Carpio F, Julian J, et al. Neurobehavioral outcomes among farm and nonfarm rural Ecuadorians. Neurotoxicol Teratol 1997:19:277-86.

31. Rohlman DS, Lasarev M, Anger WK, et al. Neurobehavioral performance of adult and adolescent agricultural workers. Neurotoxicology 2007;28:374-80.

32. Roldan-Tapia L, Nieto-Escamez FA, Aguila EM, et al. Neuropsychological sequelae from acute poisoning and long-term exposure to carbamate and organophosphate pesticides. Neurotoxicology Teratol 2006;28:694-703.

33. Jacqmin-Gadda H, Fabrigoule C, Commenges D, et al. Longitudinal study of cognitive aging in non-demented elderly subjects. Rev Epidemiol Sante Publique 1997:45:363-72.

34. Le Carret N, Auriacombe S, Letenneur L, et al. Influence of education on the pattern of cognitive deterioration in $\mathrm{AD}$ patients: the cognitive reserve hypothesis. Brain Cogn 2005;53:120-6.

35. Stern Y. Cognitive reserve and Alzheimer disease. Alzheimer Dis Assoc Disord 2006:20:112-17.

36. McCauley LA, Anger WK, Keifer M, et al. Studying health outcomes in farmworker populations exposed to pesticides. Environ Health Perspect 2006;114:953-60.

37. London L, Myers JE, Nell V, et al. An investigation into neurologic and neurobehavioral effects of long-term agrichemical use among deciduous fruit farm workers in the Western Cape, South Africa. Environ Res 1997:73:132-45.

38. Gomes J, Lloyd 0 , Revitt MD, et al. Morbidity among farm workers in a desert country in relation to long-term exposure to pesticides. Scand J Work Environ Health 1998;24:213-19.

39. Bazylewicz-Walczak B, Majczakowa W, Szymczak M. Behavioral effects of occupational exposure to organophosphorous pesticides in female greenhouse planting workers. Neurotoxicology 1999;20:819-26.

40. Moser VC. Animal models of chronic pesticide neurotoxicity. Hum Exp Toxicol 2007;26:321-31

41. Fabrigoule C, Rouch I, Taberly A, et al. Cognitive process in preclinical phase of dementia. Brain 1998;121:135-41.

42. Bäckman L. Memory and cognition in preclinical dementia: what we know and what we do not know. Can J Psychiatry 2008;53:354-60.

43. Dartigues JF, Commenges D, Letenneur D, et al. Cognitive predictors of dementia in elderly community residents. Neuroepidemiology 1997:16:29-39.

44. Tyas SL, Manfreda J, Strain LA, et al. Risk factors for Alzheimer's disease: a population-based, longitudinal study in Manitoba, Canada. Int J Epidemiol 2001:30:590-7.

45. Baldi I, Lebailly P, Mohammed-Brahim B, et al. Neurodegenerative diseases and exposure to pesticides in the elderly. Am J Epidemiol 2003:157:409-14. 